\title{
Kinetics of creation and of thermal annealing of light-induced defects in microcrystalline silicon solar cells
}

\author{
F. Meillaud ${ }^{1}{ }^{1, a)}$ E. Vallat-Sauvain, ${ }^{1}$ Arvind Shah, ${ }^{1}$ and C. Ballif ${ }^{1}$ \\ ${ }^{1}$ Institute of Microtechnology, University of Neuchâtel, Rue Breguet 2, \\ 2000 Neuchâtel, Switzerland
}

(Received 22 June 2007; accepted 15 December 2007; published online 7 March 2008)

\begin{abstract}
Single-junction microcrystalline silicon $(\mu \mathrm{c}-\mathrm{Si}: \mathrm{H})$ solar cells of selected $i$-layer crystalline volume fractions were light soaked (AM1.5, $1000 \mathrm{~h}$ at $50{ }^{\circ} \mathrm{C}$ ) and subsequently annealed at increasing temperatures. The variations of subbandgap absorption during light soaking and during thermal annealing were monitored by Fourier transform photocurrent spectroscopy. The kinetics were shown to follow stretched exponential functions over long times such as $1000 \mathrm{~h}$. The effective time constants appearing in the stretched exponential function decrease with decreasing crystalline volume fraction as well with increasing annealing temperature. Their Arrhenius-like dependence on temperature is characterized by a unique value of the activation energy. Furthermore, we demonstrate that the configuration of the solar cells $(p-i-n$ or $n-i-p)$ does not influence the degradation kinetics, as long as the average crystallinity of the intrinsic layer is of comparable value. (c) 2008 American Institute of Physics. [DOI: 10.1063/1.2844282]
\end{abstract}

\section{INTRODUCTION}

Microcrystalline silicon $(\mu \mathrm{c}-\mathrm{Si}: \mathrm{H})$ is a promising material for cost reduction of thin-film solar cells and modules; it is, in particular, proposed in association with amorphous silicon $(a-\mathrm{Si}: \mathrm{H})$ forming thereby the so-called "micromorph" tandem. ${ }^{1-3}$ Microcrystalline silicon is not a unique, welldefined material but a mixture of amorphous and nanocrystalline silicon. ${ }^{4,5}$ One of the key material parameters for the optimization of $n-i-p$ and $p-i-n$ devices is the $i$-layer crystallinity, defined as the average volume fraction of nanocrystals. This material parameter can be routinely evaluated from Raman data analysis. In typical microcrystalline silicon as grown by plasma enhanced chemical vapor deposition (PECVD), one of the easiest ways to achieve optimum $i$-layer crystallinity is to tune the silane concentration (SC) $=\mathrm{SiH}_{4} /\left(\mathrm{SiH}_{4}+\mathrm{H}_{2}\right)$ in the plasma gas phase used for the in trinsic layer deposition. SC is thus a relevant deposition parameter for the intrinsic layer fabrication. In the dilution series of microcrystalline single-junction solar cells studied here, SC is varied, whereas $p$ - and $n$-layers are maintained unchanged over the whole series. The microcrystalline material incorporated in such intrinsic layers consists of elongated nanocrystals (typical diameter around $20 \mathrm{~nm}$ ) embedded in an amorphous tissue. ${ }^{4} \mathrm{X}$-ray diffraction data reveal that, while the average crystalline volume fraction increases when $\mathrm{SC}$ is reduced, the average nanocrystal size remains almost unchanged. ${ }^{5}$ This indicates that it is probably the average thickness of amorphous material surrounding (and passivating) the nanocrystals that decreases when the average crystalline volume fraction increases.

Initially, $\mu \mathrm{c}-\mathrm{Si}: \mathrm{H}$ solar cells were presented as being fully stable under light soaking, ${ }^{6,7}$ in contrast with $a-\mathrm{Si}: \mathrm{H}$ solar cells that suffer from the Staebler-Wronski effect. ${ }^{8}$ In $a-\mathrm{Si}: \mathrm{H}$ devices, this effect results in a typical relative de-

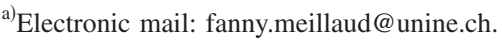

crease of the conversion efficiency by $10 \%-20 \%$ after $1000 \mathrm{~h}$ of illumination (AM1.5g spectrum at $1000 \mathrm{~W} / \mathrm{m}^{2}$ ) at a sample temperature of $50{ }^{\circ} \mathrm{C} ;{ }^{9}$ its origin has been attributed to the creation of metastable defects due to the recombination of excess electron-hole pairs. Indeed, metastable defects can also be generated by charge accumulation ${ }^{10}$ or by carrier injection. ${ }^{11}$

In this contribution, we present a study on degradation and annealing kinetics of single junction $\mu \mathrm{c}-\mathrm{Si}: \mathrm{H}$ solar cells with $i$-layers of selected crystalline volume fractions. Previous works demonstrated that some $\mu \mathrm{c}-\mathrm{Si}: \mathrm{H}$ solar cells present a milder form of light-induced degradation, depending on the crystalline volume fraction. ${ }^{12-19}$ Klein et al. ${ }^{12}$ reported a relative decrease of the conversion efficiency of up to $10 \%$ after $1000 \mathrm{~h}$ of degradation for highly amorphous $\mu \mathrm{c}-\mathrm{Si}: \mathrm{H}$ solar cells; we confirmed, by studying dilution series of $\mu \mathrm{c}-\mathrm{Si}: \mathrm{H}$ solar cells, that the higher the crystallinity, the lower the relative drop in efficiency. ${ }^{13}$ Yan et al. investigated the influence of the illumination spectra on the lightinduced degradation, ${ }^{14}$ as well as the influence of the electrical bias. ${ }^{15}$ They initially concluded that the amorphous phase was solely responsible for the light-induced degradation observed in $\mu \mathrm{c}-\mathrm{Si}: \mathrm{H}$. Nevertheless, they lately suggested that small grains and/or intermediate-range order could as well play an important role regarding the stability of $\mu \mathrm{c}-\mathrm{Si}: \mathrm{H}$ solar cells. ${ }^{16,17}$

Smirnov et al. ${ }^{18}$ showed that the decrease of photoconductivity observed in $\mu \mathrm{c}-\mathrm{Si}: \mathrm{H}$ films under light soaking is associated with the creation of metastable defects, similarly as in the case of $a-\mathrm{Si}: \mathrm{H}$. We made further observations on light-soaked single-junction $\mu \mathrm{c}-\mathrm{Si}: \mathrm{H}$ solar cells: ${ }^{13,19}$ we noted an increase of defect-related absorption, as monitored by the value of the absorption coefficient at $0.8 \mathrm{eV}$ $[\alpha(0.8 \mathrm{eV})]$ evaluated by Fourier transform photocurrent spectroscopy (FTPS) ${ }^{20}$ We suggested that light-induced defects could be spatially located at the surface of the 
nanocrystals. ${ }^{19}$ Indeed, based on well-known observations made on $a-\mathrm{Si} / c-\mathrm{Si}$ heterojunction solar cells, ${ }^{21,22}$ we proposed that the amorphous phase is necessary in the intrinsic layer in order to passivate the defects present at the surface of the nanocrystals. We focus here on the kinetics of defect creation and of thermal annealing for light-induced defects. We will show that the general trends of our experimental observations can qualitatively fit into a description already proposed for bulk amorphous silicon; this description is based on the assumption that defect creation and annealing are both mediated by the dispersive diffusion of hydrogen.

\section{EXPERIMENTAL}

Single-junction $\mu \mathrm{c}-\mathrm{Si}: \mathrm{H}$ solar cells of selected $i$-layer crystalline volume fractions were deposited by very-high frequency PECVD at $200{ }^{\circ} \mathrm{C}$ in both $p-i-n$ and $n-i$ - $p$ configurations, on glass coated with $600 \mathrm{~nm}$ thick sputtered-etched zinc oxide $(\mathrm{ZnO}){ }^{23}$ The doped layers have thicknesses in the order of $20-30 \mathrm{~nm}$, whereas the $i$-layer thickness is about $2 \mu \mathrm{m}$. Each series was deposited in a double-chamber system in order to avoid any contamination of the intrinsic layer. About $2.4 \mu \mathrm{m}$ of low-pressure chemical vapor deposited $\mathrm{ZnO}$ was used as back (front) contact for the $p-i-n(n-i-p)$ solar cells. Each solar cell has an area of about $0.25 \mathrm{~cm}^{2}$. Whereas deposition conditions for the doped layers were not modified, the intrinsic layer crystallinity was varied, for each device, by setting the silane concentration used for its deposition to a different value. The doped layers are deposited with very low silane concentrations and possess a crystalline volume fraction larger than $70 \%$ (this value is measured by Raman on doped layers deposited on $\mathrm{ZnO}$ ).

The solar cells were light soaked under AM 1.5g-like spectrum $\left(1000 \mathrm{~W} / \mathrm{m}^{2}\right)$ at $50{ }^{\circ} \mathrm{C}$ under open-circuit conditions up to $1000 \mathrm{~h}$. All samples were characterized by FTPS, $I V$, and external quantum efficiency (EQE) measurements after subsequent light-soaking time steps (i.e., after $20 \mathrm{~min}$, $1 \mathrm{~h}, 5 \mathrm{~h}, 20 \mathrm{~h}, 50 \mathrm{~h}, 100 \mathrm{~h}$, and $1000 \mathrm{~h}$ of light soaking). After $1000 \mathrm{~h}$ of light soaking, the solar cells were annealed for $10 \mathrm{~h}$ at increasing temperatures $(100,130,160$, and $180{ }^{\circ} \mathrm{C}$ ) under nitrogen flow. After each annealing, the cells were removed from the oven, measured at room temperature by FTPS and $I V / \mathrm{EQE}$, and subsequently annealed at a higher temperature. During each $10 \mathrm{~h}$ annealing, the defect-related absorption was measured stepwise after 2 and $5 \mathrm{~h}$ at room temperature. Such annealing sequences up to $180{ }^{\circ} \mathrm{C}$ were sufficient to get back to initial defect-related absorption values, as well as to initial solar cells performances (see Ref. 13 as well).

$I(V)$ measurements were performed using a WACOM sun simulator (AM1.5g spectrum, $1000 \mathrm{~W} / \mathrm{m}^{2}$ ) and a Fourier transform infrared Nicolet 8700 spectrometer was used to measure the absorption spectra of the cells between 1.6 and $0.8 \mathrm{eV} .^{20}$ The spectra were calibrated at $1.35 \mathrm{eV}$ by setting the absorption coefficient of the $\mu \mathrm{c}-\mathrm{Si}: \mathrm{H}$ cells equal to that of crystalline silicon $\left(=235 \mathrm{~cm}^{-1}\right)$. The implicit assumption underlying this calibration procedure is that defectrelated absorption $\alpha(0.8 \mathrm{eV})$ originates from the crystalline phase of the mixed-phase microcrystalline material. ${ }^{24}$
Bi-facial micro-Raman spectroscopy was performed with a $18 \mathrm{~mW}$ HeNe laser excitation beam $(633 \mathrm{~nm})$ using a long focal length objective for the measurements on the glass side. ${ }^{25}$ Micro-Raman spectroscopy was used to evaluate the average crystallinity factor $\phi_{c}$ for the intrinsic layer. Three Raman peaks were measured and deconvoluted as Gaussian peaks: one at $480 \mathrm{~cm}^{-1}$ (TO mode in amorphous silicon), one at $510 \mathrm{~cm}^{-1}$ (nanocrystals), and the third one at $520 \mathrm{~cm}^{-1}$ (TO mode in bulk crystalline silicon). The zinc oxide layers present in the solar cell do not affect the Raman spectra for $\mu \mathrm{c}-\mathrm{Si}: \mathrm{H}$ as no strong Raman mode is observed between 460 and $560 \mathrm{~cm}^{-1}$ under the measurement conditions used here. The top $n$-side (bottom $p$-side) Raman crystallinities are defined as

$$
\begin{aligned}
\phi_{c(t, b)}= & I_{c(t, b)} /\left(I_{a(t, b)}+I_{c(t, b)}\right)=\left(I_{510(t, b)}+I_{520(t, b)}\right) /\left(I_{480(t, b)}\right. \\
& \left.+I_{510(t, b)}+I_{520(t, b)}\right)
\end{aligned}
$$

where $I_{i}$ is the integrated Raman intensity area under the peak centered at $i\left(\mathrm{~cm}^{-1}\right)$ and $t$ stands for top and $b$ for bottom configuration of the measurement. In all the devices, $\phi_{c t}$ is systematically larger (relative $+10 \%-20 \%$ ) than $\phi_{c b}$. This is an indication of a Raman crystallinity increasing from the $p$-side within the $i$-layer, as usually observed in our microcrystalline devices (see, e.g., Ref. 26).

The average crystallinity factor (considered here) $\phi_{c}$ is then calculated as $\phi_{c}=\left(\phi_{c b}+\phi_{c t}\right) / 2$. Considering the light penetration depth $\mu \mathrm{c}-\mathrm{Si}: \mathrm{H}$ for a wavelength of $633 \mathrm{~nm}$ that is equal to $\sim 500 \mathrm{~nm}$, approximately $1 \mu \mathrm{m}$ of the intrinsic layer is investigated.

\section{RESULTS}

In order to follow the degradation kinetics of our $\mu \mathrm{c}-\mathrm{Si}: \mathrm{H}$ solar cells, sequential measurements of subbandgap absorption were carried out at increasing time intervals for the $1000 \mathrm{~h}$ long AM1.5 light-soaking process. We define the relative variation of defect-related absorption as

$$
\Delta \alpha(0.8 \mathrm{eV})(t)=\left[\alpha(t)-\alpha_{\text {initial }}\right] / \alpha_{\text {initial }},
$$

where $\Delta \alpha$ is presented as a function of light-soaking time in Fig. 1 for $p-i-n$ and $n-i-p$ dilution series of single-junction $\mu \mathrm{c}-\mathrm{Si}: \mathrm{H}$ solar cells.

A relative increase of defect-related absorption is observed with light-soaking time for all samples, in both $p-i-n$ and $n-i-p$ configurations. In agreement with previous observations, ${ }^{13,19}$ the solar cells incorporating an intrinsic layer of lower crystallinity degrade more than the devices incorporating $i$-layers of higher crystallinity. Furthermore, the results of Fig. 1 show that the solar cell configuration $(n-i-p$ or $p-i-n)$ does not affect the degradation kinetics, as long as the average $i$-layer crystallinity is of comparable value.

The relative increase in defect-related absorption over long times (quasisaturation values of defect-related absorption are reached after about $500 \mathrm{~h}$ of light soaking) can be well fitted with a stretched exponential functionl, 


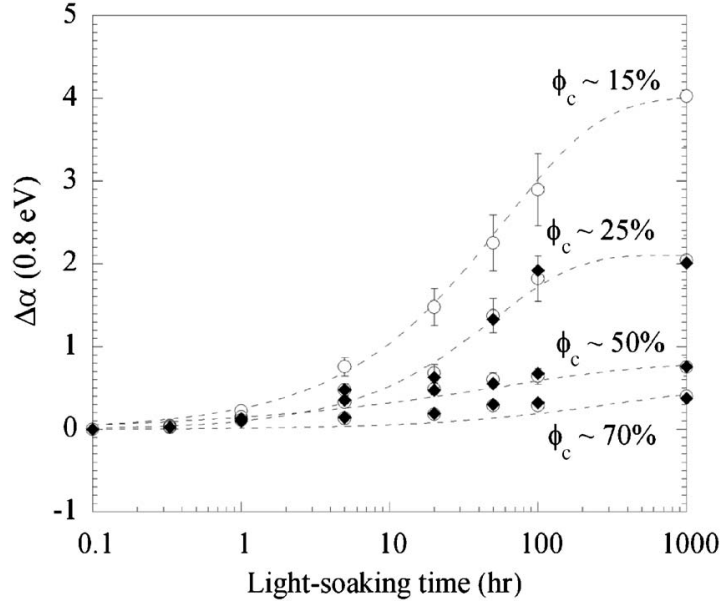

FIG. 1. Relative increase of defect-related absorption as a function of lightsoaking time for single-junction $\mu \mathrm{c}-\mathrm{Si}: \mathrm{H}$ solar cells $(n-i-p$ : empty dots and $p-i-n$ : full rhombs), with $i$-layer Raman crystallinity factors $\phi_{c}$ ranging from $15 \%$ to $70 \%$. The dotted lines are fits according to Eq. (3).

$$
\begin{aligned}
\Delta \alpha(0.8 \mathrm{eV})(t)= & \left(\frac{\alpha_{\mathrm{ss}}(0.8 \mathrm{eV})-\alpha_{\text {initial }}(0.8 \mathrm{eV})}{\alpha_{\text {initial }}(0.8 \mathrm{eV})}\right) \\
& \times\left\{1-\exp \left[\left(-\frac{t}{\tau}\right)^{\beta}\right]\right\}
\end{aligned}
$$

where $\alpha_{\mathrm{sS}}$ is the quasisaturation value of the defect-related absorption, $\alpha_{\text {initial }}$ the initial value, $\beta$ and $\tau$ the dispersion parameter and the effective time constant, respectively.

From the fits of the degradation kinetics presented in Fig. 1, we establish a value for the dispersive parameter $\beta$ $\sim 0.60$, independent of $\phi_{c}$, whereas $\tau$ increases with crystallinity from $\tau \sim 7 \times 10^{4} \mathrm{~s}$ for $\phi_{c} \sim 15 \%$ to $\tau \sim 1.2 \times 10^{6} \mathrm{~s}$ for $\phi_{c} \sim 70 \%$. The relative increase of defect-related absorption with light-soaking time is thus observed to be slower in $\mu \mathrm{c}-\mathrm{Si}: \mathrm{H}$ than in $a-\mathrm{Si}: \mathrm{H}$, with, also, a larger value of $\beta$ ( $\beta$ $\sim 0.60$ instead of 0.45$){ }^{27}$

The relative decrease of $\alpha(0.8 \mathrm{eV})$ with annealing time can as well be fitted with a stretched exponential function, as shown in Fig. 2 for the $n-i-p$ dilutions series. The fit parameters $\tau$ and $\beta$ are very similar for both series $( \pm 5 \%)$.

In this case, $\Delta \alpha$ decreases with annealing time according to

$$
\begin{aligned}
\Delta \alpha(0.8 \mathrm{eV})(t)= & \left(\frac{\alpha_{\mathrm{ss}}(0.8 \mathrm{eV})-\alpha_{\text {initial }}(0.8 \mathrm{eV})}{\alpha_{\text {initial }}(0.8 \mathrm{eV})}\right) \\
& \times\left\{\exp \left[-\left(\frac{t}{\tau}\right)^{\beta}\right]\right\}
\end{aligned}
$$

Equation (4) is verified here for annealing temperatures ranging from 373 to $453 \mathrm{~K}$ (see results of Fig. 3 for the highly amorphous $n-i-p$ sample). Again, we obtain values for the dispersive parameter $\beta$ that are independent of $\phi_{c}$ ( $\beta$ ranges from $\sim 0.69$ at $T_{a}=373 \mathrm{~K}$ to $\sim 0.82$ at $\left.T_{a}=453 \mathrm{~K}\right)$ as well as values for the effective time constant $\tau$ that increase with increasing crystallinity (see Fig. 4). Furthermore, as verified in Fig. 4, $\tau$ may be expressed as a function of the annealing temperature through the expression

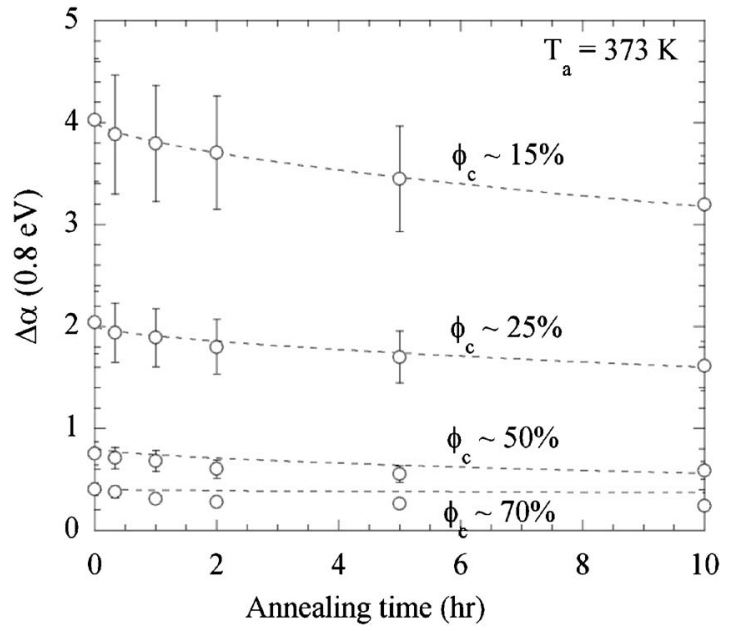

FIG. 2. Relative decrease of defect-related absorption as a function of annealing time for $n-i-p$ solar cells, with Raman crystallinity factors $\phi_{c}$ $\sim 15 \%$ to $\phi_{c} \sim 70 \%$ at an annealing temperature of $373 \mathrm{~K}$. The dotted lines are fits according to Eq. (4).

$$
\tau=\tau_{0} \exp \left(\frac{E_{a}}{k T_{a}}\right)
$$

with $E_{a}$ the activation energy and $T_{a}$ the annealing temperature.

According to Eq. (5), the data of Fig. 4 yield a value for $E_{a}$ (as given by the slope of the fit), which is equal to $0.5 \mathrm{eV}$ and which is independent of the $i$-layer crystalline volume fraction. This value for $E_{a}$ is smaller here than the published values for amorphous silicon $(\sim 1 \mathrm{eV}){ }^{28,29}$

Since the kinetics of $\alpha(0.8 \mathrm{eV})$ during light soaking and thermal annealing of the single-junction $\mu \mathrm{c}-\mathrm{Si}: \mathrm{H}$ solar cells presented here and the kinetics of dangling bond creation and annealing in $a-\mathrm{Si}: \mathrm{H}$ can similarly be fitted with stretched exponential functions, we suggest that a similar microscopic mechanism is underlying both processes in these two mate-

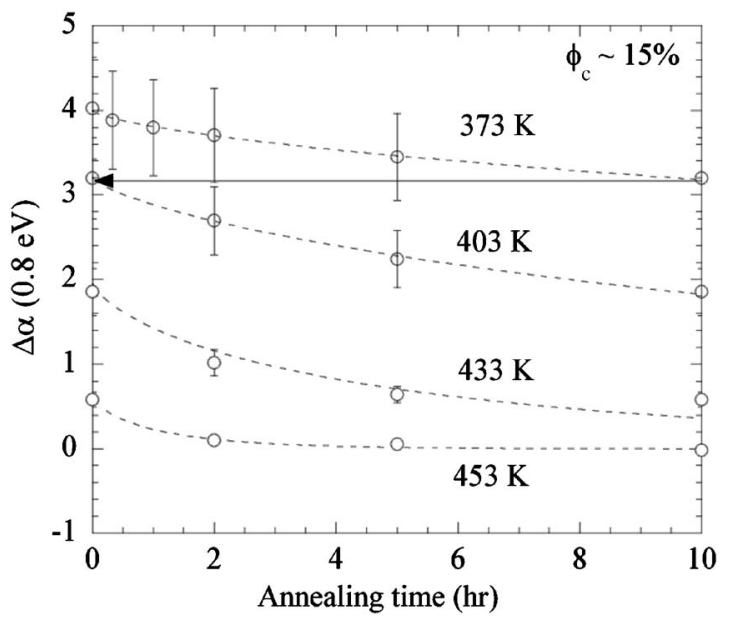

FIG. 3. Relative decrease of defect-related absorption as a function of annealing time for the highly amorphous $n-i-p$ solar cell $\left(\phi_{c}=15 \%\right)$ for annealing temperatures from 373 to $453 \mathrm{~K}$. The dotted lines are fits according to Eq. (4). After each $10 \mathrm{~h}$ annealing at a given temperature, annealing is restarted again at higher temperature as indicated by an arrow for the first and second annealings (end point at $373 \mathrm{~K}$ corresponds to starting point at $403 \mathrm{~K})$. 


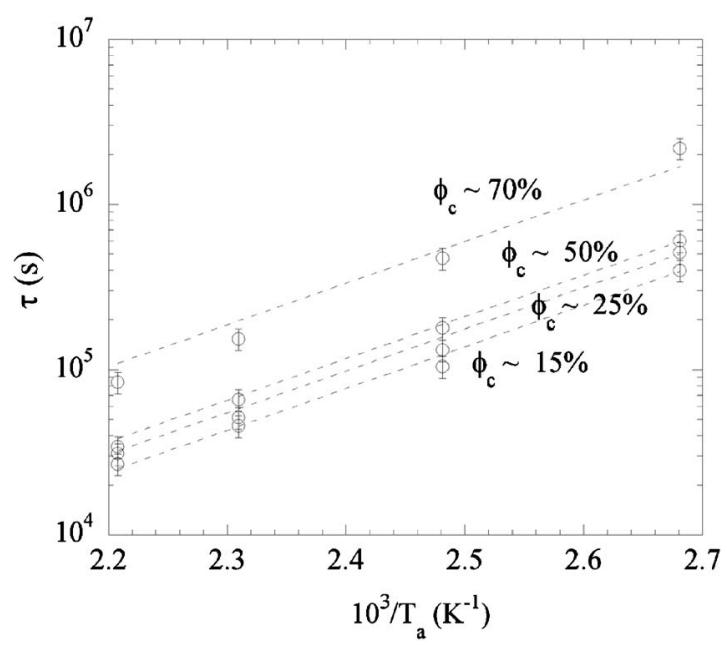

FIG. 4. Effective time constant $\tau$ for defect annealing as a function of the reciprocal of the annealing temperature for the four $n-i-p$ samples. The dotted lines are fits according to Eq. (5) with $E_{a}=0.5 \mathrm{eV}$.

rials. As a consequence, Eq. (5) should also be valid for light soaking at $323 \mathrm{~K}$. Accordingly, an activation energy equal to $0.4 \mathrm{eV}$ is found here for defect creation using data of Fig. 1 and Eq. (3).

\section{DISCUSSION}

Since the primary observations of the Staebler-Wronski effect, several models have been proposed to describe the kinetics of light-induced defect creation and annealing in amorphous silicon. ${ }^{27-34}$ Even though the models differ in some aspects, it is commonly accepted now that the diffusion of hydrogen within the amorphous material somehow triggers the creation and annealing of dangling bonds. Dispersive diffusion of hydrogen is thus the limiting step in the creation and annealing of defects, a mechanism which results in stretched exponential kinetics. As shown above, in the case of microcrystalline silicon as well, both defect creation and annealing kinetics can be fitted over long times with stretched exponential functions. Nevertheless, larger values of the dispersive parameter $(\beta \sim 0.70 \pm 0.10)$, longer effective time constants $\tau$ as well as lower activation energies $\left(E_{a} \sim 0.4-0.5 \mathrm{eV}\right)$ are obtained here, as compared to typical values for $a-\mathrm{Si}: \mathrm{H}$. Furthermore, the increase of $\tau$ with increasing crystallinity (see Fig. 4) is another original observation. The description of dispersive diffusion of Hydrogen in $a-\mathrm{Si}: \mathrm{H}$ (Refs. 31-34) may be described using the paradigm model of dipole relaxation by Shlesinger and Montroll ${ }^{35}$ In this model, the event (annealing of a dangling bond, assumed to sit at the origin of an infinite space lattice) is triggered by the arrival at that point of any of the (initially) uniformly distributed Hydrogen on the lattice. By assuming a power law like pausing time distribution for hydrogen motion, the survival probability of the dangling bond at the origin follows a stretched exponential decay. Thus, in analogy with $a$-Si:H, we can speculate that the stretched exponential increase of surface defects during light soaking, as observed here, could result from bond breaking at the nanocrystals surface. Note that if any bond breaking occurs in the amorphous phase, it is not detected by FTPS at $0.8 \mathrm{eV}$ according to our calibration procedure. ${ }^{24}$ However, complementary experimental techniques such as, e.g., electron spin resonance, ${ }^{36,37}$ electrically detected magnetic resonance, ${ }^{38}$ or photoluminescence spectroscopy ${ }^{39}$ allow the identification of dangling bonds in different structural environments as well as anisotropic defects. These techniques could help elucidate the respective roles of hydrogen diffusion, dangling bonds in the amorphous phase, and defects at the nanocrystals surface on $\mu \mathrm{c}-\mathrm{Si}: \mathrm{H}$ stability.

From our FTPS data, we can speculate that the surface bond-breaking mechanism could be triggered by danglingbond diffusion, mediated by hydrogen dispersive motion through the amorphous layer as present between the nanocrystals. In this case, the thickness of this layer is critical for the kinetics of light-induced degradation in $\mu \mathrm{c}-\mathrm{Si}: \mathrm{H}$. Depending on the detailed microstructure of the material, the mechanism of defect diffusion through the amorphous layer could relate the kinetics of degradation to the average crystalline volume fraction of $\mu \mathrm{c}-\mathrm{Si}: \mathrm{H}$. It is not clear, however, whether one should consider (a) the $a-\mathrm{Si}: \mathrm{H}$ material as an infinite reservoir of defects, in which case the H-mediated diffusion of defects could be considered as the limiting step for surface defect creation, or whether (b) it is the slow increase of defects within the amorphous material combined with their diffusion toward the nanocrystals surface that results in the observed kinetics of defect creation. In both pictures, a dangling bond "hitting" the surface of the nanocrystals after a random walk with a power-law distribution of pausing time would result in the creation of an additional surface defect. Such model has not been developed yet and the experimental data presented above certainly need further interpretation. Identification of the microscopic nature of light-induced defects (both within the amorphous phase and at the nanocrystals surface) in $\mu \mathrm{c}-\mathrm{Si}: \mathrm{H}$ with complementary experimental techniques would certainly help to elucidate the mechanism describing the metastability of $\mu \mathrm{c}-\mathrm{Si}: \mathrm{H}$. Furthermore, hydrogen diffusion coefficients should be measured in our microcrystalline devices and compared to reported values for amorphous silicon, ${ }^{34}$ polymorphous silicon, ${ }^{40}$ and polycrystalline silicon, ${ }^{41,42}$ where diffusion is linked to grain boundaries.

\section{CONCLUSIONS}

The study of light-induced degradation kinetics and of thermal annealing kinetics of $\mu \mathrm{c}-\mathrm{Si}: \mathrm{H}$ single-junction solar cells incorporating $i$-layers of different crystallinities has been presented. Here, we demonstrate that degradation and thermal annealing kinetics for $\mu \mathrm{c}-\mathrm{Si}: \mathrm{H}$ can be fitted with stretched exponential functions, as in the case of $a-\mathrm{Si}: \mathrm{H}$. However, the degradation and thermal recovery kinetics presented here for $\mu \mathrm{c}-\mathrm{Si}: \mathrm{H}$ devices are slower than in bulk $a$-Si:H layers, with corresponding larger values of the fit parameters (i.e., larger dispersive coefficient $\beta$ and effective time constants $\tau$ ). Both fit parameters are shown to depend on the crystalline volume fraction of the photoactive $i$-layer material. In order to gain additional insights into the exact mechanism responsible for light-induced degradation $\mu \mathrm{c}-\mathrm{Si}: \mathrm{H}$ devices, further developments are needed of a 
model based on the dispersive diffusion of hydrogen that takes into account the detailed microstructure of $\mu \mathrm{c}-\mathrm{Si}: \mathrm{H}$.

\section{ACKNOWLEDGMENTS}

This work was supported by the Swiss Federal Office for energy OFEN (project 101191) and the Swiss National Science Foundation (FN-20001-107469).

${ }^{1}$ A. Shah, J. Meier, E. Vallat-Sauvain, N. Wyrch, U. Kroll, C. Droz, and U. Graf, Sol. Energy Mater. Sol. Cells 78, 469 (2003).

${ }^{2}$ J. Meier, J. Spitznagel, U. Kroll, C. Bucher, S. Faÿ, T. Moriarty, and A. Shah, Proceedings of the third WCPEC, Osaka, 2003 (unpublished), p. 2801.

${ }^{3}$ S. Fukuda, K. Yamamoto, A. Nakajima, M. Yoshimi, T. Sawada, T. Suezaki, M. Ichikawa, Y. Koi, M. Goto, T. Meguro, T. Matsuda, T. Sasaki, and Y. Tawada, Proceedings of the 21st EU PVSEC, Dresden, Germany, 2006 (unpublished), p. 1535.

${ }^{4}$ E. Vallat-Sauvain, U. Kroll, J. Meier, A. Shah, and J. Pohl, J. Appl. Phys. 87, 3137 (2000).

${ }^{5}$ J. Bailat, E. Vallat-Sauvain, L. Fetiknecht, C. Droz, and A. Shah, J. Appl. Phys. 93, 5725 (2003).

${ }^{6}$ J. Meier, R. Flückiger, H. Keppner, and A. Shah, Appl. Phys. Lett. 65, 860 (1994).

${ }^{7}$ K. Yamamoto, IEEE Trans. Electron Devices 46, 2041 (1999).

${ }^{8}$ D. L. Staebler and C. R. Wronski, Appl. Phys. Lett. 31, 292 (1977).

${ }^{9}$ S. Benagli, U. Kroll, J. Meier, D. Borrello, J. Spitznagel, G. Androutsopoulos, G. Monteduro, D. Zimin, O. Kluth, T. Roschek, C. Ellert, W. Stein, G. Buechel, A. Buechel, and D. Koch-Ospelt, Proceedings of the 21st EUPVSEC, Dresden, Germany, 2006 (unpublished), p. 1719.

${ }^{10}$ W. B. Jackson and M. D. Moyer, Phys. Rev. B 36, 6217 (1987).

${ }^{11}$ R. A. Street, Appl. Phys. Lett. 59, 1084 (1991).

${ }^{12}$ S. Klein, F. Finger, R. Carius, T. Dylla, B. Rech, M. Grimm, L. Houben, and M. Stutzmann, Thin Solid Films 430, 202 (2003).

${ }^{13}$ F. Meillaud, E. Vallat-Sauvain, X. Niquille, M. Dubey, J. Bailat, A. Shah, and C. Ballif, Proceedings of the 31st IEEE PVSC, Orlando, USA, 2005 (unpublished), p. 1412.

${ }^{14}$ B. Yan, G. Yue, J. M. Owens, J. Yang, and S. Guha, Appl. Phys. Lett. 85 1925 (2004)

${ }^{15}$ G. Yue, B. Yan, J. Yang, and S. Guha, Appl. Phys. Lett. 86, 092103 (2005).

${ }^{16}$ G. Yue, B. Yan, G. Ganguly, J. Yang, S. Guha, and C. W. Teplin, Appl. Phys. Lett. 88, 263507 (2006).

${ }^{17}$ G. Yue, B. Yan, G. Ganguly, J. Yang, and S. Guha, J. Mater. Res. 22, 1128 (2007).

${ }^{18}$ V. Smirnov, S. Reynolds, F. Finger, C. Main, and R. Carius, "Amorphous and nanocrystalline silicon science and technology - 2004," MRS Symposia Proceedings No. 808 (Materials Research Society, Pittsburgh, 2004), p. 47.

${ }^{19}$ F. Meillaud, E. Vallat-Sauvain, X. Niquille, D. Dominé, A. Shah, and C. Ballif, Proceedings of the 21st EUPVSEC, Dresden, Germany, 2006 (unpublished), p. 1729.

${ }^{20}$ M. Vanecek and A. Poruba, Appl. Phys. Lett. 80, 719 (2002).

${ }^{21}$ H. Keppner, P. Torres, R. Flückiger, J. Meier, A. Shah, C. Fortmann, P. Fath, G. Willeke, K. Happle, and H. Kiess, Sol. Energy Mater. Sol. Cells 34, 201 (1994).

${ }^{22}$ A. Laades, K. Kliefoth, L. Korte, K. Brendel, R. Stangl, M. Schmidt, and W. Fuhs, Proceedings of the 19th EUPVSEC, Paris, 2004 (unpublished), p. 1170.

${ }^{23}$ J. Hüpkes, B. Rech, S. Calnan, O. Kluth, U. Zastrow, H. Siekmann, and M. Wuttig, Thin Solid Films 502, 286 (2006).

${ }^{24}$ J. Bailat, E. Vallat-Sauvain, M. Dubey, F. Meillaud, X. Niquille, J. Guillet, A. Shah, A. Poruba, L. Mullerova, J. Springer, and M. Vanecek, Proceedings of the 19th EUPVSEC, Paris, 2004 (unpublished), p. 1541.

${ }^{25}$ C. Droz, E. Vallat-Sauvain, J. Bailat, L. Feitknecht, J. Meier, and A. Shah, Sol. Energy Mater. Sol. Cells 81, 61 (2004).

${ }^{26}$ J. Bailat, E. Vallat-Sauvain, L. Feitknecht, C. Droz, and A. Shah, J. Appl. Phys. 93, 5727 (2003).

${ }^{27}$ D. Redfield and R. H. Bube, Appl. Phys. Lett. 54, 1037 (1989).

${ }^{28}$ W. B. Jackson and K. Kakalios, Phys. Rev. B 37, 1020 (1988).

${ }^{29}$ M. Stutzmann, W. B. Jackson, and C. C. Tsai, Phys. Rev. B 32, 23 (1985).

${ }^{30}$ R. A. Street, Hydrogenated Amorphous Silicon (Cambridge University Press, Cambridge, 1991)

${ }^{31}$ J. Kakalios and W. B. Jackson, Amorphous Silicon and Related Materials (World Scientific, Singapore, 1988), p. 207.

${ }^{32}$ W. B. Jackson, J. M. Marshall, and M. D. Moyer, Phys. Rev. B 39, 1164 (1989).

${ }^{33}$ H. Branz, Solid State Commun. 105, 387 (1998).

${ }^{34}$ H. Branz, Phys. Rev. B 60, 7725 (1999).

${ }^{35}$ M. F. Shlesinger and E. W. Montroll, Proc. Natl. Acad. Sci. U.S.A. 81, 1280 (1984).

${ }^{36}$ A. L. Baia Neto, A. Lambertz, R. Carius, and F. Finger, J. Non-Cryst. Solids 299-302, 274 (2002).

${ }^{37}$ K. Morigaki and C. Niikura, Solid State Commun. 136, 308 (2005).

${ }^{38}$ C. Boehme and K. Lips, J. Non-Cryst. Solids 338, 434 (2004).

${ }^{39}$ T. Merdzhanova, R. Carius, S. Klein, F. Finger, and D. DimovaMalinovska, Thin Solid Films 511-512, 394 (2006).

${ }^{40}$ E. F. Kail, S. Fellah, A. Abramov, A. Hadjadj, and P. Roca i Cabarrocas, J. Non-Cryst. Solids 352, 1083 (2006).

${ }^{41}$ J. K. Rath, R. E. I. Schropp, and W. B. Beyer, Solid State Phenom. 80-81, 109 (2001)

${ }^{42}$ N. H. Nickel, W. B. Jackson, and J. Walker, J. Non-Cryst. Solids 227-230, 885 (1998) 